Tema: Engenharia de superfície

\title{
MAPAS DE DESGASTE MICROABRASIVO DO AÇO INOXIDÁVEL AUSTENÍTICO AISI 316L: UMA ANÁLISE COMPARATIVA DE SUPERFÍCIES NÃO NITRETADAS E NITRETADAS A PLASMA*
}

\author{
João Paulo Calixto da Silva ${ }^{1}$ \\ Cherlio Scandian² \\ Adonias Ribeiro Franco Júnior ${ }^{3}$
}

Resumo

Os modos de desgaste de um material podem sofrer transições decorrentes de alterações nas condições do tribossistema. Para o estudo e análise dos fenômenos associados às eventuais mudanças, a técnica de micro-abrasão do tipo esfera livre é reconhecidamente uma boa escolha. No presente trabalho, para o aço inoxidável austenítico AISI 316L, fez-se um estudo do comportamento da taxa de desgaste, bem como do mecanismo de desgaste em função da carga de ensaio, tipo de abrasivo $\left(\mathrm{SiO}_{2}\right.$ ou $\mathrm{SiC}$ ), dureza do material (modificada pela sua nitretação) e concentração de abrasivo. O desgaste por deslizamento predomina quando a lama abrasiva é constituída de $\mathrm{SiO}_{2}$, enquanto o rolamento passa a prevalecer com a troca do abrasivo para o SiC. Verificou-se que em nenhum dos dois casos ocorreu transição de mecanismos após variações nas condições de ensaio. Por outro lado, o coeficiente de desgaste do material aumenta com a carga de ensaio, substituição do $\mathrm{SiO}_{2}$ pelo $\mathrm{SiC}$ e tende a cair com a nitretação (aumento de dureza) do aço e com a concentração de abrasivo. O aumento simultâneo da carga de ensaio e da concentração de sílica na lama diminui significativamente a taxa de desgaste, encurtando o período de "running-in".

Palavras-chave: Desgaste microabrasivo; Mapas de desgaste; Aço inoxidável austenítico AISI 316L.

\section{MICRO-ABRASION WEAR MAPPING FOR AISI 316L STAINLESS STEEL: A COMPARATIVE ANALYSIS ON UNTREATED AND PLASMA NITRIDED SURFACES \\ Abstracts}

The transition in the wear mechanisms of a material can occur owing to changes on the tribosystem conditions. "Free ball" micro-scale abrasion method is widely used for studying the associated phenomena. In this work, the behavior of both the wear coefficient and wear mechanism for the 316 stainless steel was studied as a function of the testing load, abrasive $\left(\mathrm{SiC}\right.$ or $\mathrm{SiO}_{2}$ ) as well their concentration in the slurry, and material hardness (untreated and plasma nitrided). Grooving wear was found to be dominant when using $\mathrm{SiO}_{2}$ slurries, whereas wear in $\mathrm{SiC}$ slurries is dominated by the mechanism of rolling. In spite of no transition in the wear mechanisms when changed the testing conditions, it was found a trend in the wear coefficient to increase whether at high loads or replacing $\mathrm{SiO}_{2}$ by $\mathrm{SiC}$, and to fall down when the steel is nitrided (hardened) and low slurry concentrations are used. A decreasing in both the wear coefficient and "running-in" step was observed when the testing load and $\mathrm{SiO}_{2}$ concentration are simultaneously increased.

Keywords: Micro-scale abrasion wear; Wear maps; AISI 316L austenitic stainless steel.

1 Engenheiro Mecânico, Mestrando em engenharia metalúrgica, PROPEMM, IFES, Vitória, ES, Brasil

2 Engenheiro Metalurgista, Mestre em engenharia metalúrgica, Doutor em Science et Ingénierie des Materiaux, Professor Doutor, UFES, Vitória, ES, Brasil.

3 Engenheiro Metalurgista, Mestre em engenharia de materiais, Doutor em Engenharia metalúrgica Professor Doutor, IFES, Vitória, ES, Brasil.

* Technical contribution to the $1^{\text {st }}$ Workshop on surface treatments of corrosion resistant alloys, July $21^{\text {st }}-25^{\text {th }}$, 2014, São Paulo, SP, Brazil. 


\section{INTRODUÇÃO}

O estudo da compreensão dos mecanismos que levam ao desgaste dos materiais, assim como a influência das condições às quais o material está submetido, é alvo de diversos pesquisadores [1-4]. A definição de desgaste abrasivo segundo a norma ASTM G40-96 é o desgaste devido a partículas ou protuberâncias duras forçadas contra uma superfície sólida e que se movem ao longo dessa superfície. O desgaste microabrasivo está inserido nesse contexto e pode ser classificado de forma diferente. Duas classificações para os modos de desgaste microabrasivo são predominantes. Gates [5] sugere que o desgaste seja classificado em função da severidade, e dividido em três regimes: leve, severo e extremo. Já em estudos mais recentes, Adachi e Hutchings [6] investigaram a transição dos modos de desgaste, classificando-os em: desgaste a dois corpos e desgaste a três corpos. Ainda a respeito do modo de desgaste e da transição entre os modos, Trezona, Allsopp e Hutchigs [7] estudaram a influência dos parâmetros do tribosistema na transição entre o regime de desgaste de dois corpos para o de três corpos. A terminologia adotada nesse trabalho será a mesma que foi abordada por Adachi e Hutchings [6]. O teste de desgaste microabrasivo por esfera livre, conhecido como "ball-cratering", vem sendo muito utilizado no estudo do desgaste de materiais, sendo possível analisar a influência dos parâmetros como carga e concentração de abrasivo, sob os mecanismos de desgaste. Para ensaios do tipo esfera rotativa (livre e fixa), Cozza et al. [2] apresentaram um estudo correlacionando a severidade de ensaio ao modo de desgaste. No método por esfera livre, após uma esfera ser rotacionada contra a amostra na presença de uma lama de abrasivo, obtém-se uma calota na superfície da amostra. A geometria da calota, assim como a profundidade e o volume de massa removido dependem da combinação dos parâmetros carga, concentração de abrasivo e distância deslizada, os quais são controlados durante o ensaio. Uma vez que o diâmetro da esfera é conhecido e as velocidades angulares devidamente selecionadas e controladas, pode-se por meio da equação de Archard calcular o coeficiente de desgaste, $\mathrm{K}$, com unidades em $\mathrm{m}^{3}(\mathrm{~N} \mathrm{~m})^{-1}$. A equação de Archard, relaciona o volume de desgaste, $\mathrm{V}$, a distância de deslizamento, $\mathrm{L}$, e a força normal aplicada, Fn, através da equação:

$$
K=\frac{V}{L . F n}
$$

O volume desgastado pode ser calculado em função do diâmetro da esfera e do diâmetro externo da calota:

$$
V=\frac{\pi \cdot b^{4}}{32 . \phi}
$$

onde: $b$ - diâmetro de impressão da calota; $\phi$ - diâmetro da esfera

E a distância de deslizamento através da equação 3:

$$
L=\frac{19,95 . n_{2} \cdot \phi}{\sqrt{\frac{\phi^{2}}{4}-25}}
$$

onde: $n_{2}$ - número de rotações do eixo motriz do equipamento.

O aço inoxidável AISI 316L apresenta boas características de resistência à corrosão em diversos ambientes, com um preço relativamente baixo. A liga é muito utilizada em diversos segmentos da indústria, podendo-se destacar: química, papel e

\footnotetext{
* Technical contribution to the $1^{\text {st }}$ Workshop on surface treatments of corrosion resistant alloys, July $21^{\text {st }}-25^{\text {th }}, 2014$, São Paulo, SP, Brazil.
} 
celulose, petróleo e gás, farmacêutica e nuclear. Apesar da sua boa resistência à corrosão, um dos fatores que mais causam danos ao material, é o desgaste abrasivo em sua superfície [8].

A nitretação a plasma é uma das formas mais eficientes de se elevar a resistência ao desgaste do aço AISI 316L, sem reduzir a sua resistência à corrosão. Trabalhos recentes apontam um aumento significativo na resistência ao desgaste do aço AISI 316L, quando submetido ao tratamento de nitretação a plasma. De acordo com Picard et al. [11], o nitrogênio intersticial promove o endurecimento do material sem que ocorra uma redução da resistência à corrosão. A camada que se forma em decorrência da supersaturação em nitrogênio da austenita, é conhecida por austenita expandida ou fase $\mathrm{S}$, que é a responsável pelo aumento da resistência ao desgaste do material.

Diversos trabalhos analisam a influência dos parâmetros de nitretação a plasma sob a resistência ao desgaste do aço AISI 316L. Entretanto, ainda é pouco exploradoo modo de desgaste de superfícies metálicas em diferentes condições.

Este trabalho tem como objetivo analisar os modos de desgaste, assim como mapear as possíveis transições entre os dois modos, para o aço inoxidável 316L nitretado a plasma e não nitretado, submetidos a diferentes condições de concentração de abrasivo e de carga do ensaio de microabrasão por esfera livre.

\section{MATERIAIS E MÉTODOS}

As amostras utilizadas nesse estudo foram de aço inoxidável AISI 316L com um diâmetro de aproximadamente $25,4 \mathrm{~mm}$ e espessura de aproximadamente $5 \mathrm{~mm}$. A composição química do material foi determinada em espectrômetro de emissão óptica da marca Oxford Instruments, modelo Foundry-Master Pro, localizado no IFES. A composição química apresentada na tabela 1 mostra que 0 aço se caracteriza como inoxidável austenítico do tipo AISI 316 L.

Tabela 1. Composição química do aço inoxidável AISI 316L (\% em peso)

\begin{tabular}{cccccccccccc}
\hline $\mathrm{Cr}$ & $\mathrm{Ni}$ & $\mathrm{Mo}$ & $\mathrm{Mn}$ & $\mathrm{Cu}$ & $\mathrm{Si}$ & $\mathrm{Co}$ & $\mathrm{Nb}$ & $\mathrm{C}$ & $\mathrm{Sn}$ & $\mathrm{P}$ & $\mathrm{S}$ \\
16,2 & 10,6 & 2,26 & 1,77 & 0,40 & 0,39 & 0,11 & 0,04 & 0,03 & 0,01 & 0,03 & 0,02 \\
\hline
\end{tabular}

Todas as amostras foram lixadas da lixa 80 até a de 600 mesh e em seguida polidas com pasta de alumina de granulometria de 1 e 0,3 $\mu \mathrm{m}$ antes da realização dos ensaios.

Para a realização dos ensaios de desgaste, foi utilizado o equipamento de microabrasão "Ball Cratering" (Calowear), da marca CSM Instruments, pertencente ao laboratório de Engenharia de superfícies do IFES, Figura 1.

\footnotetext{
* Technical contribution to the $1^{\text {st }}$ Workshop on surface treatments of corrosion resistant alloys, July $21^{\text {st }}-25^{\text {th }}, 2014$, São Paulo, SP, Brazil.
} 


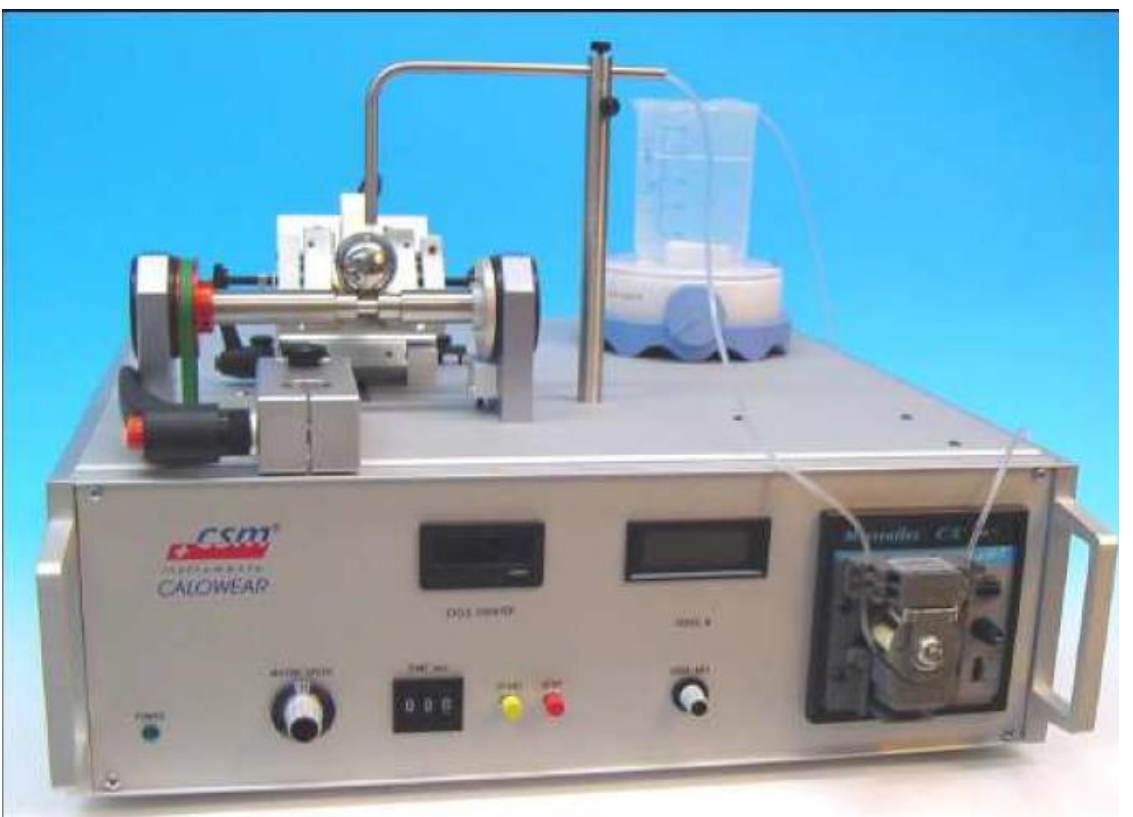

Figura 1. Calowear - Equipamento para ensaio de desgaste microabrasivo usado nesse estudo.

Os abrasivos selecionados para o ensaio foram o carbeto de silício ( $\mathrm{SiC}$ ) grau F1200, com tamanho médio das partículas em aproximadamente $4 \mu \mathrm{m}$ e dióxido de Silício $\left(\mathrm{SiO}_{2}\right) \mathrm{S} 5631$, com tamanho médio de partículas em aproximadamente 1 a 5 $\mu \mathrm{m}$.

A esfera de aço martensítico AISI 52100 usada possui um diâmetro de 25,4mm. Para evitar possíveis efeitos hidrodinâmicos entre a esfera e o eixo da máquina, a sua rotação foi fixada em $150 \mathrm{rpm}$, valor normalmente utilizado em ensaios com esse tipo de equipamento.

As cargas de ensaio utilizadas, tanto para as amostras nitretadas quanto para as não nitretadas, foram: $0,23 \mathrm{~N}, 0,28 \mathrm{~N}$ e $0,33 \mathrm{~N}$. Para cada carga foram utilizadas 3 concentrações de lama diferentes, sendo: $0,75 \mathrm{~g} / \mathrm{cm}^{3}$ (75 gramas de abrasivo em $100 \mathrm{ml}$ de água destilada), $0,60 \mathrm{~g} / \mathrm{cm}^{3}$ (60 gramas de abrasivo em $100 \mathrm{ml}$ de água destilada) e $0,30 \mathrm{~g} / \mathrm{cm}^{3}$ (30 gramas de abrasivo em $100 \mathrm{ml}$ de água destilada), sendo que para cada concentração analisada, o coeficiente de desgaste foi calculado em intervalos de: 1500, 3000, 6000 e 9000 revoluções do eixo motor, possibilitando o cálculo da distância de deslizamento.

As análises das crateras de desgaste foram feitas com o auxílio de um microscópio óptico acoplado ao equipamento de microabrasão, o que permitiu acompanhar a evolução das crateras de desgaste com a distância deslizada e, consequentemente, calcular a profundidade de desgaste, volume desgastado e, com isso, o coeficiente de desgaste em função da distância percorrida.

Para análise da superfície as amostras foram examinadas por microscopia eletrônica de varredura, no equipamento modelo EVO MA10 da marca Zeiss instalado no IFES, campus Vitória.

A nitretação a plasma foi realizada em reator a plasma pulsado da marca SDS modelo Thor NP 5000 pertencente ao laboratório de Engenharia de Superfícies do IFES.

As amostras foram nitretadas por um período de 3 horas em atmosfera de $75 \%$ de nitrogênio e $25 \%$ de hidrogênio, sob pressão de aproximadamente 3 Torr. e tensão de $537 \mathrm{~V}$.

\footnotetext{
* Technical contribution to the $1^{\text {st }}$ Workshop on surface treatments of corrosion resistant alloys, July $21^{\text {st }}-25^{\text {th }}$, 2014, São Paulo, SP, Brazil.
} 


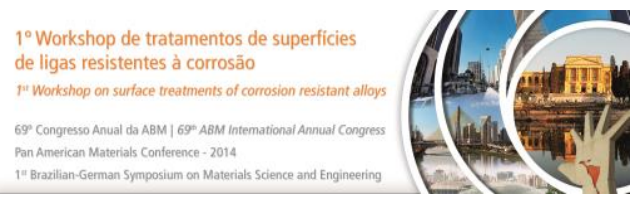

\section{RESULTADOS E DISCUSSÃO}

\subsection{Modos de Desgaste}

Tanto as amostras de aço 316 nitretadas quanto as não nitretadas após ensaio com lama abrasiva de dióxido de silício $\left(\mathrm{SiO}_{2}\right)$ apresentaram desgaste com predomínio do mecanismo de abrasão a dois-corpos. A Figura 2 compara a superfície da amostra nitretada com a da não nitretada. Essas superfícies de desgaste foram produzidas sob as mesmas condições de carga e concentração de abrasivo.
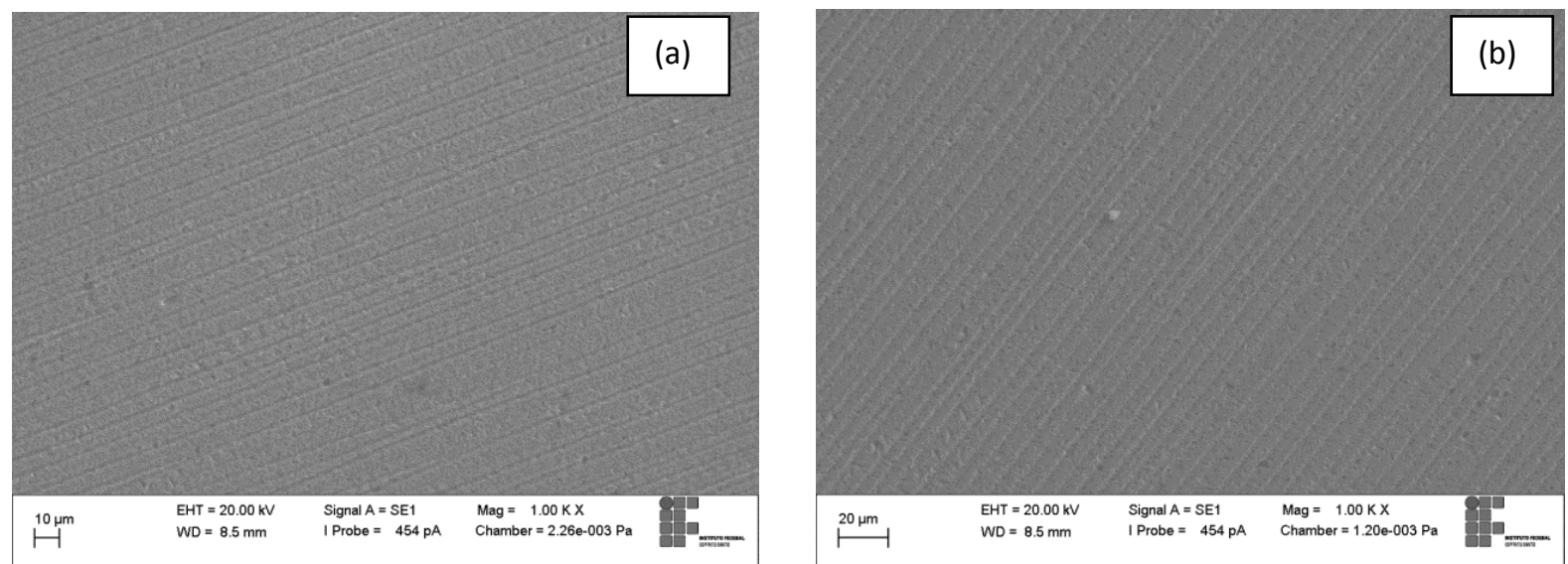

Figura 2. Superfície de desgaste do aço AISI 316L (a) não nitretado e (b) nitretado, após ensaio de desgaste microabrasivo realizado sob carga normal de $0,23 \mathrm{~N}$, concentração de $\mathrm{SiO}_{2}$ de $30 \mathrm{~g} / 100 \mathrm{ml}$. Ampliação 1000X.

O desgaste por dois corpos (deslizamento) ocorre quando algumas partículas se aderem à superfície da esfera e atuam como penetradores fixos, produzindo diversas ranhuras paralelas [7], conforme mostram as imagens na Figura 1.

Constatou-se que o mecanismo de três-corpos(rolamento) foi predominante em todas as amostras ensaiadas com lama abrasiva de SiC, seja nas amostras nitretadas ou não nitretadas, independentemente da carga e concentração de abrasivo utilizados no ensaio. A Figura 3 compara a superfície de desgaste da amostra nitretada com a da não nitretada, produzidas sob as mesmas condições de carga e concentração de abrasivo.
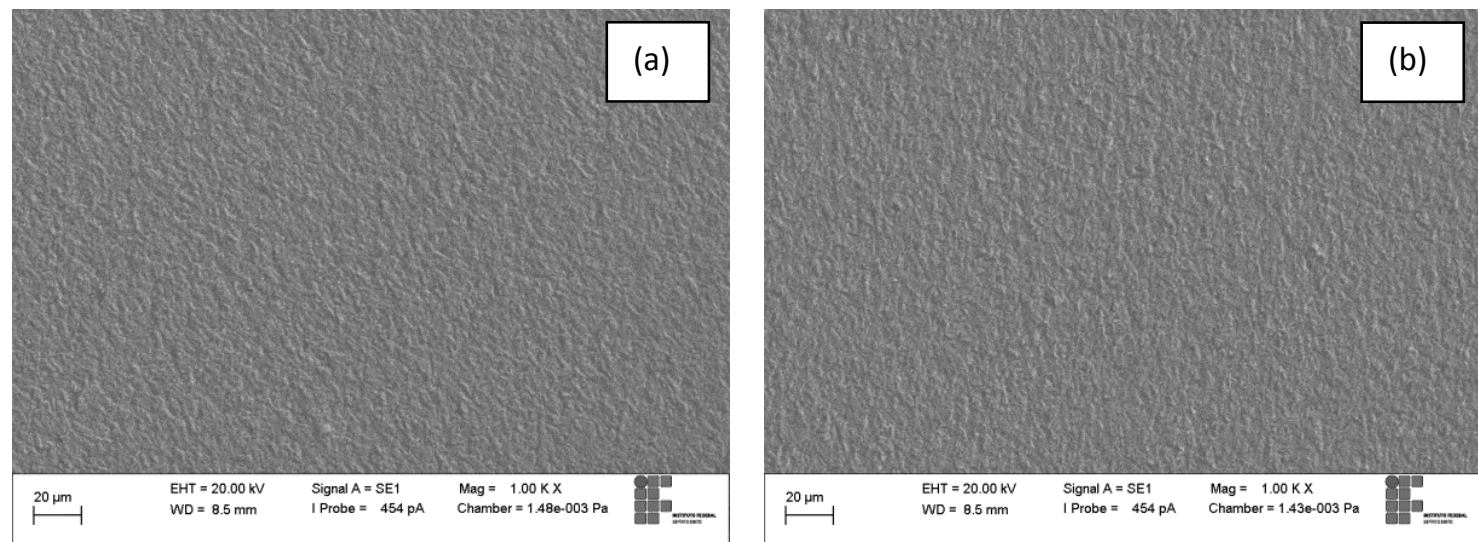

Figura 3. Superfície de desgaste do aço AISI 316L (a) não nitretado e (b) nitretado, após ensaio de desgaste microabrasivo realizado sob carga normal de $0,23 \mathrm{~N}$, concentração de $\mathrm{SiC}$ de $30 \mathrm{~g} / 100 \mathrm{ml}$. Ampliação 1000X.

\footnotetext{
* Technical contribution to the $1^{\text {st }}$ Workshop on surface treatments of corrosion resistant alloys, July $21^{\text {st }}-25^{\text {th }}$, 2014, São Paulo, SP, Brazil.
} 


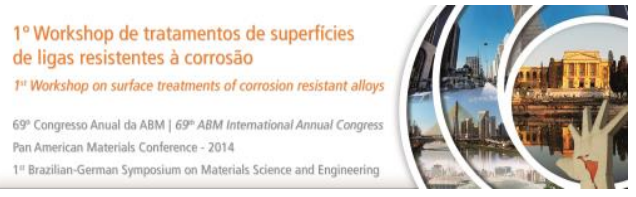

No desgaste por três corpos (ou rolamento) as partículas abrasivas não se aderem à superfície da esfera, rolando aleatoriamente de forma a provocar diversas indentações na amostra [7] conforme mostra a Figura 3.

Adachi e Hutchings [6] identificaram mudanças no modo de desgaste em função da variação das condições de ensaio, tais como carga e concentração de abrasivo, sendo possível mapear os pontos onde a transição de um modo para outro ocorria. Já no presente trabalho, essa análise não foi possível, uma vez que com o uso do abrasivo $\mathrm{SiO}_{2}$ o desgaste a dois corpos prevaleceu em todas as condições de ensaio, seja para amostras nitretadas ou não nitretadas, enquanto com o uso de $\mathrm{SiC}$ verificou-se uma predominância da abrasão a três corpos.

\subsection{Volume Removido pelo Desgaste}

A variação do volume de desgaste foi analisada em função da concentração de abrasivo, carga normal aplicada e tipo de abrasivo ( $\mathrm{SiC}$ e $\mathrm{SiO}_{2}$ ), tanto para as amostras nitretadas quanto para as não nitretadas. Para as amostras ensaiadas com $\mathrm{SiC}$ não se verificou uma mudança significativa do volume removido com a carga de ensaio. As Figuras 4 e 5 apresentam o comportamento de desgaste da amostra não nitretada, em termos de volume removido em função da distância de deslizamento, sob ensaio com lamas de diferentes concentrações de SiC.

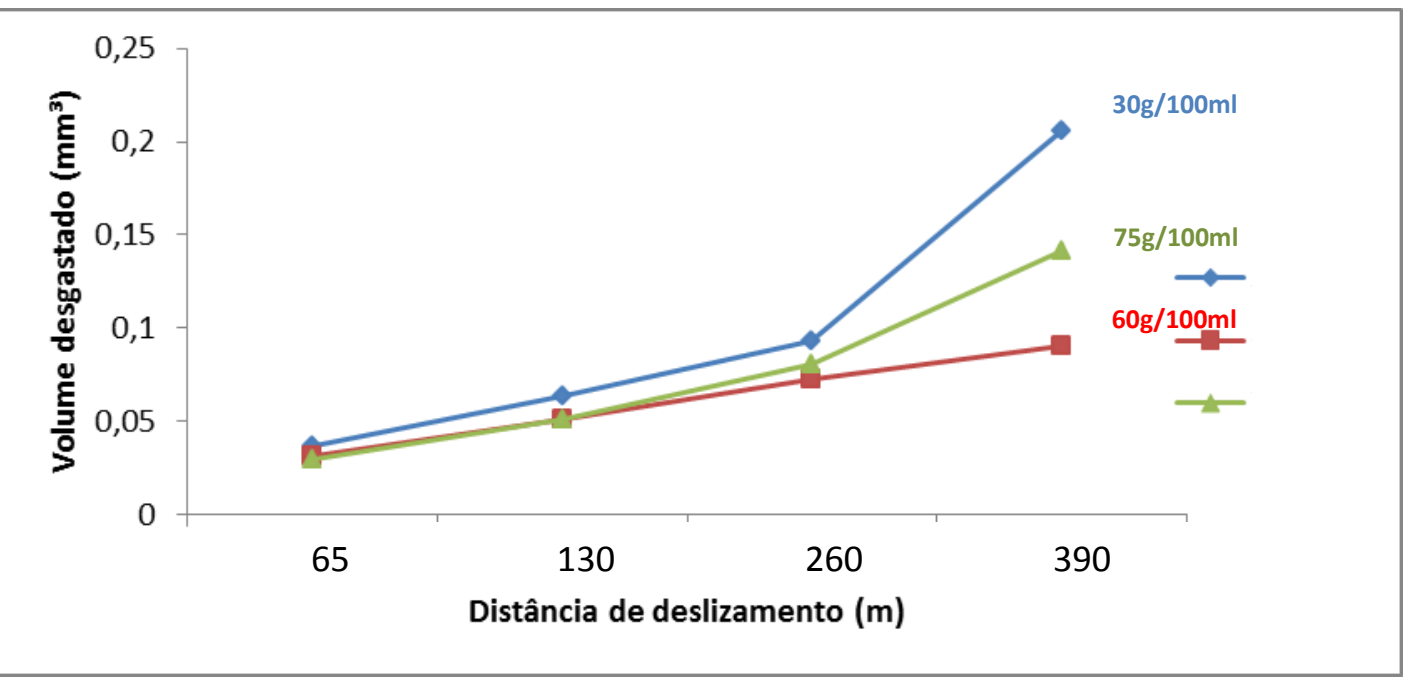

Figura 4. Variação do volume de desgaste em função da distância de deslizamento para o aço 316 (não nitretado) ensaiado em diferentes concentrações de SiC. Carga de ensaio de 0,23N.

* Technical contribution to the $1^{\text {st }}$ Workshop on surface treatments of corrosion resistant alloys, July $21^{\text {st }}-25^{\text {th }}$, 2014, São Paulo, SP, Brazil. 

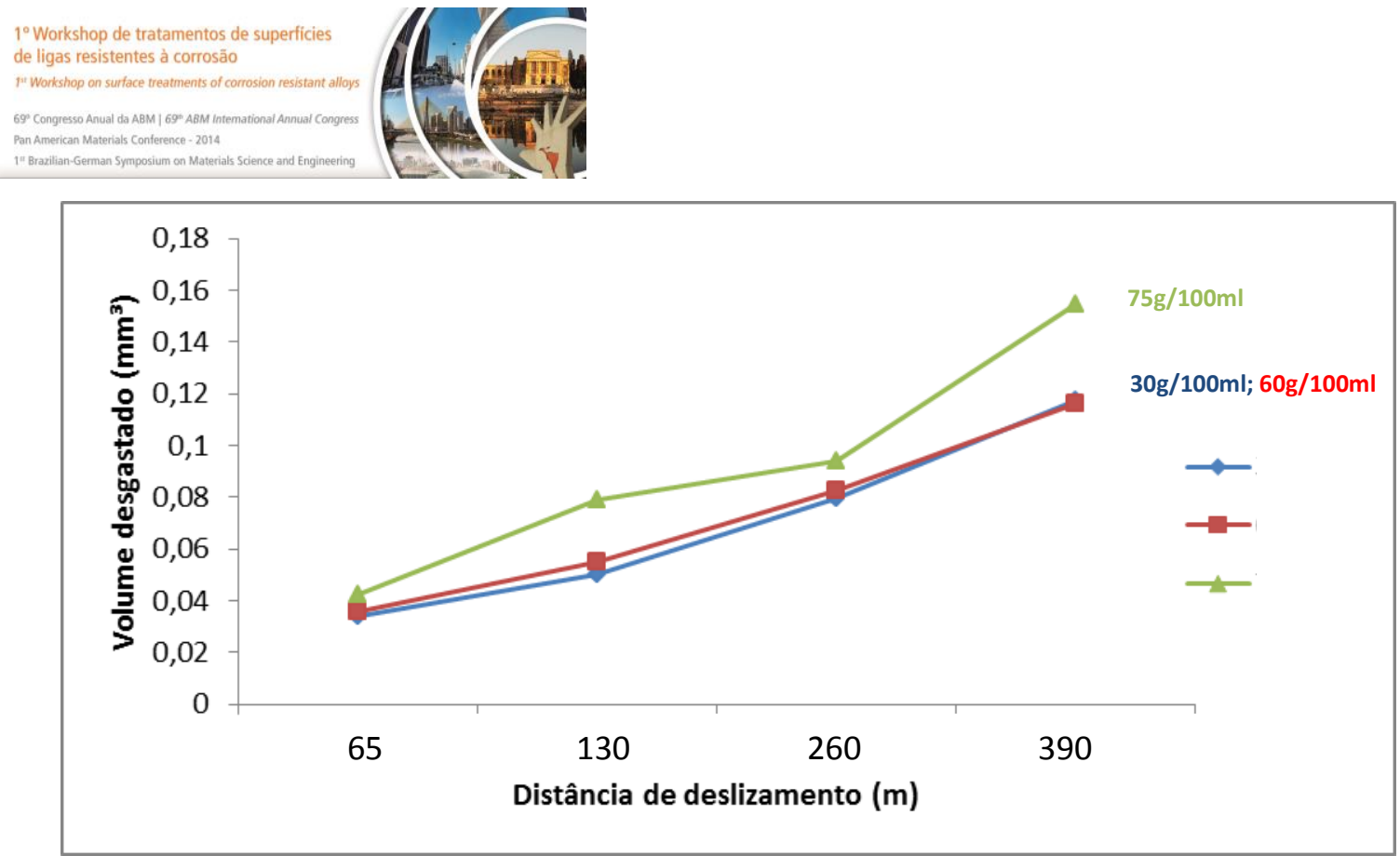

Figura 5. Variação do volume de desgaste em função da distância de deslizamento para o aço 316L (não nitretado) ensaiado em diferentes concentrações de SiC. Carga de ensaio de 0,33N.

As amostras nitretadas apresentaram de forma geral uma redução de aproximadamente $12 \%$ de volume desgastado de material quando submetidas às mesmas condições de ensaio que as amostras não nitretadas.

Nas Figuras 6 e 7 é mostrado o comportamento de desgaste da amostra nitretada, em termos de volume removido em função da distância de deslizamento, sob ensaio de desgaste em lamas de diferentes concentrações de $\mathrm{SiO}_{2}$.

O volume removido foi proporcional ao aumento da carga normal de ensaio, conforme mostram as Figuras 6 e 7.

Infere-se também que maiores volumes desgastados podem ser obtidos, quando usadas menores concentrações de lama abrasiva.

Comparando as Figuras 4 e $5 \mathrm{com}$ as Figuras 6 e 7, verifica-se que as amostras ensaiadas com lama de $\mathrm{SiC}$ apresentaram um maior volume desgastado do que aquelas ensaiadas com $\mathrm{SiO}_{2}$, sob as mesmas condições de ensaio.

As amostras nitretadas tiveram uma diminuição no volume de desgaste em média $14 \%$ menor que as amostras não nitretadas quando submetidas ao ensaio com lama de $\mathrm{SiO}_{2}$, conforme mostram as Figuras 6 e 7.

Parece que o uso excessivo de abrasivo na lama favorece a formação de uma camada de proteção, constituída pelo abrasivo propriamente dito, localizada entre a esfera e amostra, o que resulta em menor volume de desgaste.

* Technical contribution to the $1^{\text {st }}$ Workshop on surface treatments of corrosion resistant alloys, July $21^{\text {st }}-25^{\text {th }}, 2014$, São Paulo, SP, Brazil. 


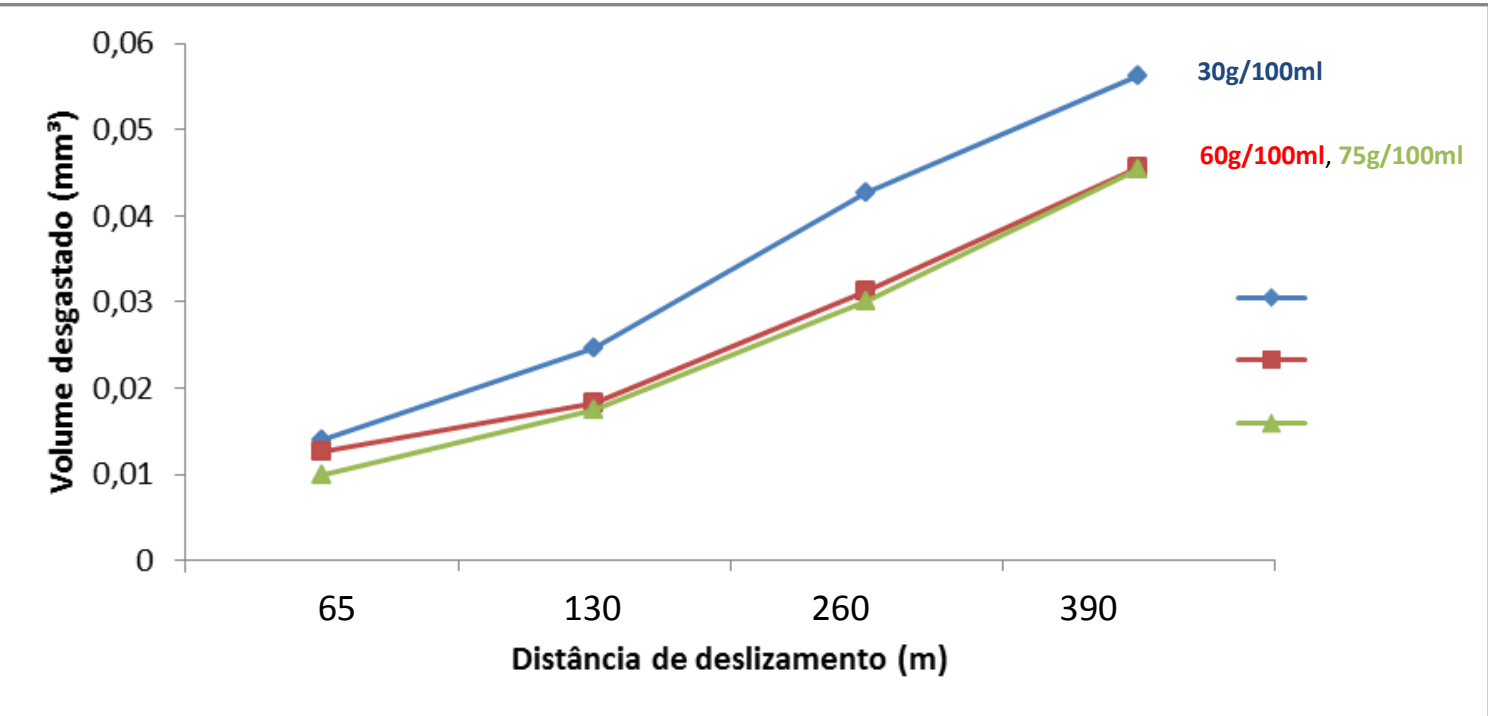

Figura 6. Variação do volume de desgaste em função da distância de deslizamento para o aço 316L (nitretado) ensaiado em diferentes concentrações de $\mathrm{SiO}_{2}$. Carga de ensaio de 0,28N.

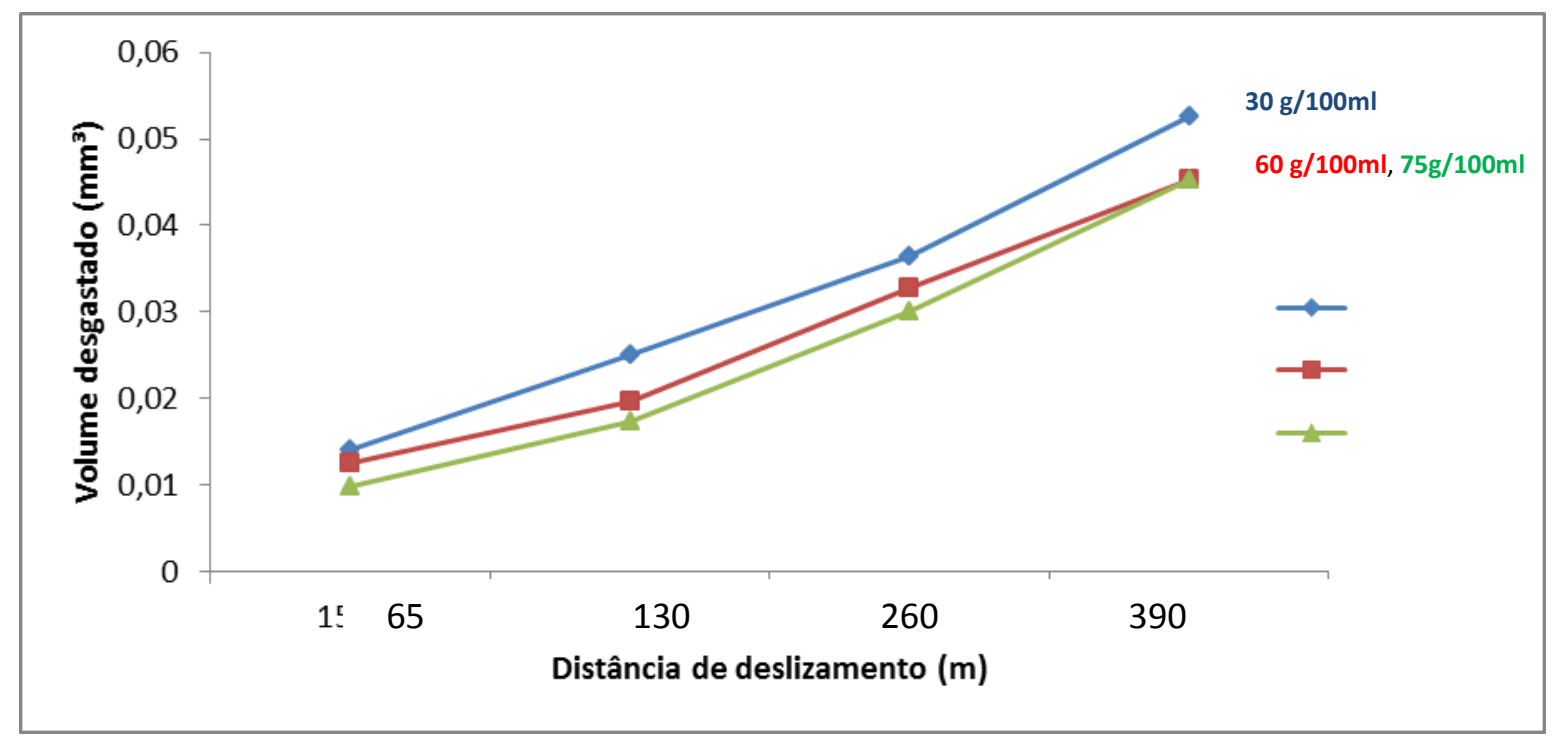

Figura 7. Variação do volume de desgaste em função da distância de deslizamento para 0 aço 316 (nitretado) ensaiado em diferentes concentrações de $\mathrm{SiO}_{2}$. Carga de ensaio de 0,33N.

\subsection{Coeficiente de Desgaste}

As Figuras 8 a 10 apresentam a variação do coeficiente de desgaste em função da distância de deslizamento para a amostra de aço 316 (não nitretado) ensaiada sob diferentes cargas e concentrações de $\mathrm{SiO}_{2}$.

Para a amostra nitretada, o aumento na resistência ao desgaste foi de aproximadamente $8 \%$ quando o ensaio é realizado com lama abrasiva de $\mathrm{SiC}$ e de $11 \%$ quando a sílica $\left(\mathrm{SiO}_{2}\right)$ é usada como partícula abrasiva. Gobbi [10], estudando o aço ferramenta AISI D2 sob diferentes condições do ensaio de microabrasão tipo esfera livre, verificou um aumento de $15 \%$ na resistência ao desgaste microabrasivo do material. Já Bôrtoli [8] obteve um aumento significativo na resistência ao desgaste do aço AISI 316L após nitretação, verificando em alguns casos uma diminuição de $67 \%$ no volume de desgaste.

* Technical contribution to the $1^{\text {st }}$ Workshop on surface treatments of corrosion resistant alloys, July $21^{\text {st }}-25^{\text {th }}$, 2014, São Paulo, SP, Brazil. 


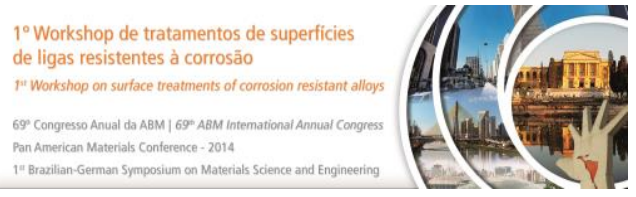

Com o uso de baixas concentrações de $\mathrm{SiO}_{2}\left(30 \mathrm{~g} / 100 \mathrm{ml}\right.$ de $\left.\mathrm{H}_{2} \mathrm{O}\right)$, a Figura 8 indica que ocorre uma tendência de diminuição na taxa de desgaste com o aumento da carga de ensaio.

A Figura 9 mostra que o uso de concentrações intermediárias de $\mathrm{SiO}_{2}(60 \mathrm{~g} / 100 \mathrm{ml}$ de $\left.\mathrm{H}_{2} \mathrm{O}\right)$ e de cargas moderadas $(0,28 \mathrm{~N})$ resulta em menor taxa de desgaste. São praticamente iguais as taxas de desgaste obtidas com cargas de 0,23 e 0,33 N.

Já altas concentrações de $\mathrm{SiO}_{2}\left(75 \mathrm{~g} / 100 \mathrm{ml}\right.$ de $\left.\mathrm{H}_{2} \mathrm{O}\right)$ e altas cargas de ensaio não só promovem uma queda significativa na taxa de desgaste, como também proporcionam a passagem para o regime de desgaste permanente [12] em uma distância de deslizamento bem mais curta, conforme indica a Figura 10.

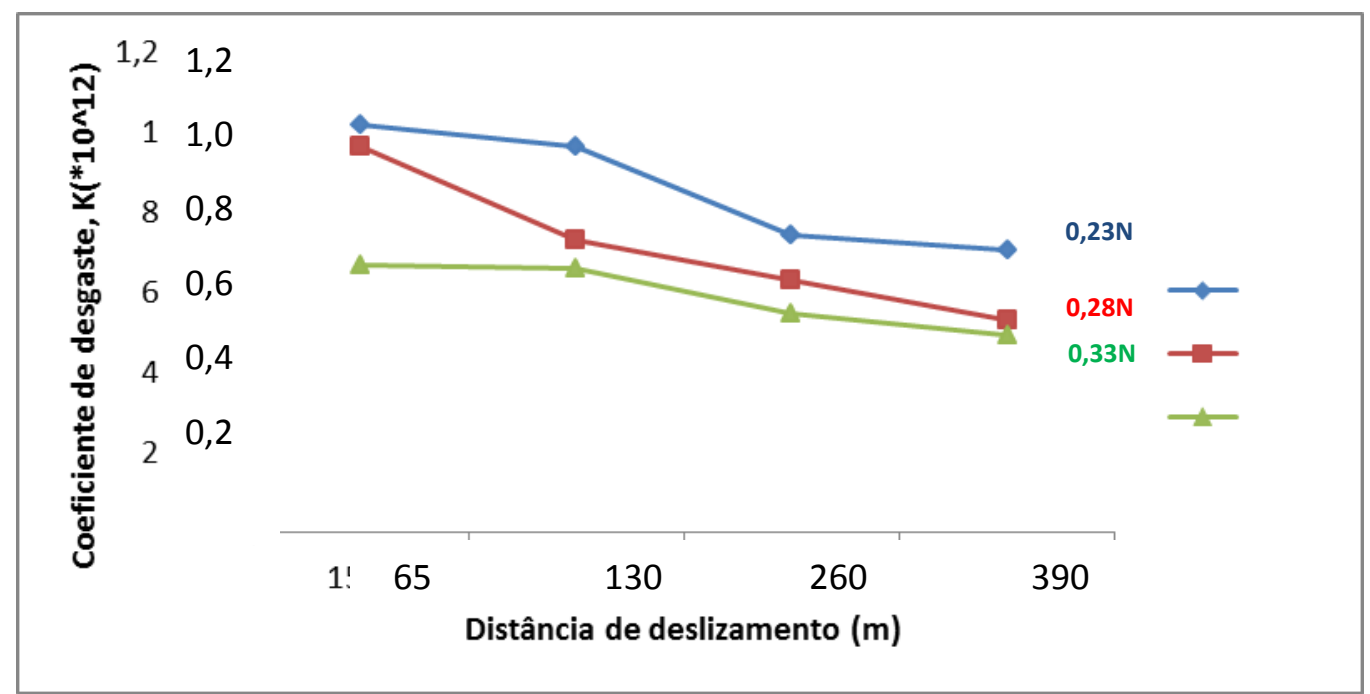

Figura 8. Variação do coeficiente de desgaste com a distância de deslizamento para o aço 316 (não nitretado) ensaiado sob diferentes cargas. Concentração de $\mathrm{SiO}_{2} 30 \mathrm{~g} / 100 \mathrm{ml}$ de $\mathrm{H}_{2} \mathrm{O}$

Conforme mostrado nessas Figuras, o regime permanente de desgaste [9] não foi atingido por nenhuma das amostras. Para todas as amostras, no entanto, parece existir uma tendência de estabilização nos valores de coeficiente a partir de $390 \mathrm{~m}$.

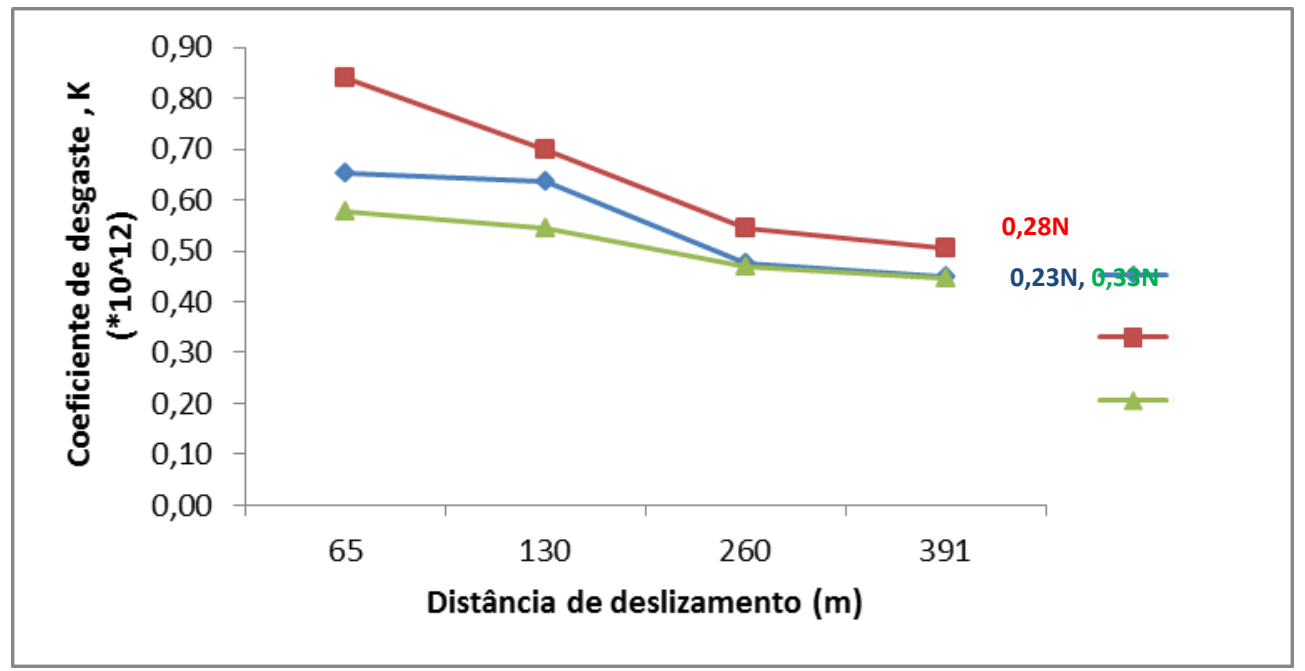

Figura 9. Variação do coeficiente de desgaste com a distância de deslizamento para o aço 316 (não nitretado) ensaiado sob diferentes cargas. Concentração de $\mathrm{SiO}_{2}: 60 \mathrm{~g} / 100 \mathrm{ml}$ de $\mathrm{H}_{2} \mathrm{O}$.

\footnotetext{
* Technical contribution to the $1^{\text {st }}$ Workshop on surface treatments of corrosion resistant alloys, July $21^{\text {st }}-25^{\text {th }}, 2014$, São Paulo, SP, Brazil.
} 

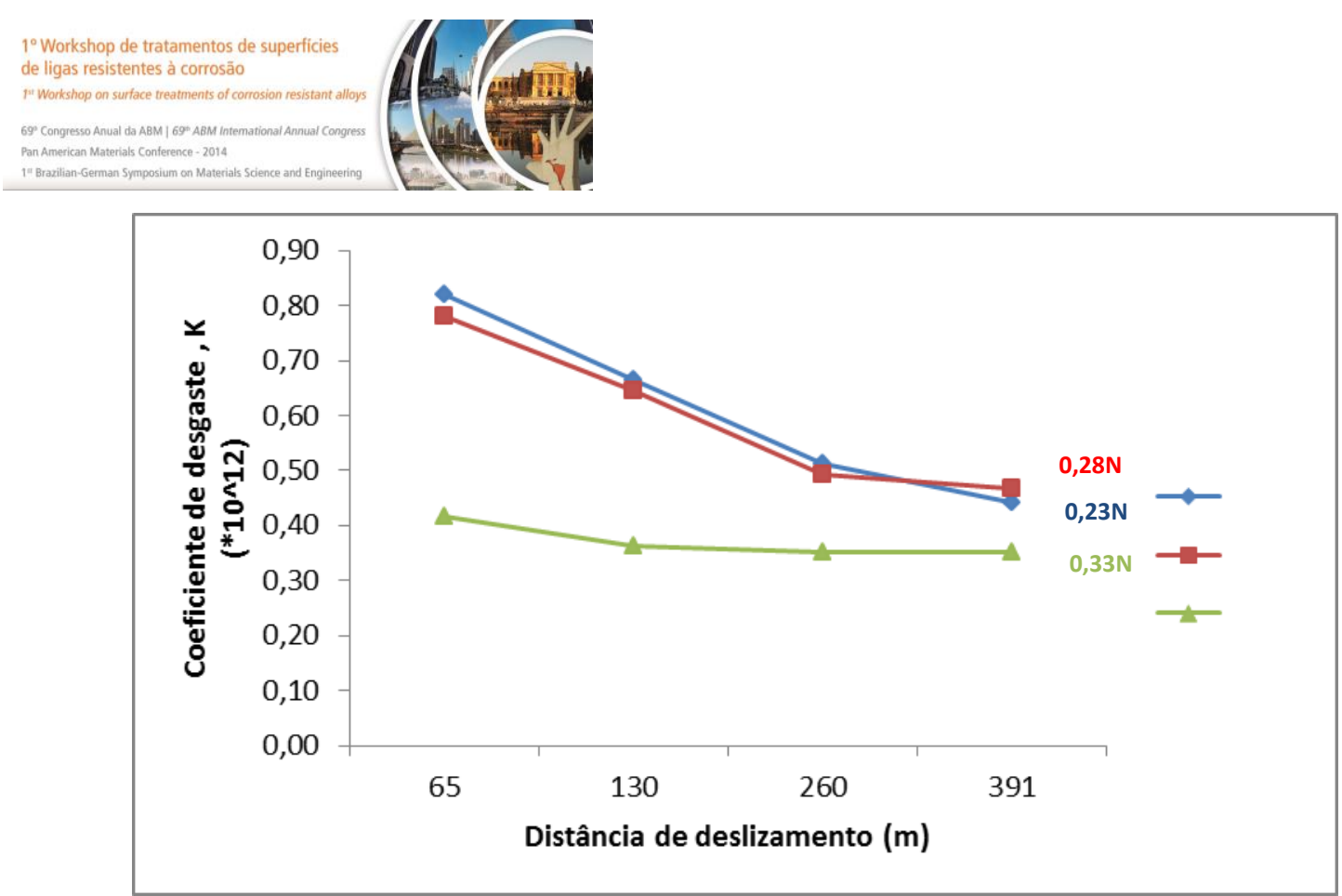

Figura 10. Variação do coeficiente de desgaste com a distância de deslizamento para o aço 316 (não nitretado) ensaiado sob diferentes cargas. Concentração de $\mathrm{SiO}_{2}: 75 \mathrm{~g} / 100 \mathrm{ml} \mathrm{de} \mathrm{H}_{2} \mathrm{O}$.

\section{CONCLUSÃo}

O desgaste do aço inoxidável austenítico AISI 316L se dá predominantemente por deslizamento quando no ensaio de microabrasão se usa o dióxido de silício $\left(\mathrm{SiO}_{2}\right)$, ocorrendo uma transição para o mecanismo de rolamento após substituição desse abrasivo pelo carbeto de silício ( $\mathrm{SiC}$ ).

$\mathrm{Em}$ ambos os casos $\left(\mathrm{SiO}_{2}\right.$ ou $\left.\mathrm{SiC}\right)$, não se observa transição de mecanismos com a alteração da carga de ensaio, concentração de abrasivo e dureza do material (conseguida pela nitretação do aço)

O coeficiente de desgaste aumenta com a carga de ensaio, substituição da sílica pelo carbeto de silício e tende a cair com a nitretação (aumento de dureza) do aço e com o aumento da concentração de abrasivo.

O uso excessivo de abrasivo na lama provavelmente favorece a formação de uma camada de proteção localizada entre o contra-corpo e o material, diminuindo o seu desgaste abrasivo.

No caso do aço 316L nitretado, o aumento simultâneo da carga de ensaio e da concentração de sílica na lama não só provoca uma queda significativa na taxa de desgaste como também favorece a entrada do desgaste em regime permanente em distâncias percorridas mais curtas.

\section{Agradecimentos}

Os autores agradecem a Ricardo Salvador Boldrini, Laboratório de Microscopia Eletrônica de Varredura do IFES, campus Vitória, pelas imagens de MEV.

\section{REFERÊNCIAS}

1 Rutherford KL, Hutchings IM. Theory and application of a micro-scale abrasive wear test. Journal of Testing and Evaluation, 1997;25(2):250-260.

2 Adachi K, Hutchings IM. Sensitivity of wear rates in the micro-scale abrasion test to test conditions and material hardness. Wear. 2005;258:318-321.

3 Cozza RC, Mello JDB, Tanaka DK, Souza RM. Relationship between test severity and wear mode transition in micro-abrasive wear tests. Wear, 2007;263:111-116.

* Technical contribution to the $1^{\text {st }}$ Workshop on surface treatments of corrosion resistant alloys, July $21^{\text {st }}-25^{\text {th }}$, 2014, São Paulo, SP, Brazil. 


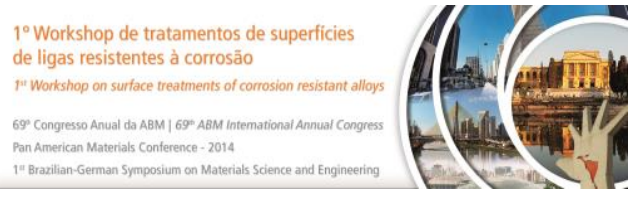

4 Batista JCA, Joseph MC, Godoy C, Matthews A. Micro-Abrasion wear testing of PVD TiN coatings on untreatad and plasma nitride AISI H13 steel. Wear. 2002;249:971-979.

5 Gates JD. Two-body and three-body abrasion: A critical discussion. Wear. 1998:214:139-146.

6 Adachi K, Hutchings IM. Wear-mode mapping for the micro-scale abrasion test. Wear. 2003;255:23-29.

7 Trezona RI, Allsopp DN, Hutchings IM. Transitions between two-body and three-body abrasive wear: influence of test conditions in the microscale abrasive wear test. Wear. 1999;225-229:205-214.

8 Bôrtoli EB. Estudo da resistência ao desgaste microabrasivo de camadas de austenita expandida produzidas em aço inoxidável austenítico AISI 316L nitretado a plasma [dissertação pós-graduação em Engenharia Metalúrgica e de Materiais]. Vitória: Instituto Federal do Espírito Santo; 2013.

9 Cozza RC. Estudo do comportamento do coeficiente de desgaste e dos modos de desgaste abrasivo em ensaios de desgaste micro-abrasivo [dissertação mestrado]. São Paulo: Escola Politécnica da Universidade de São Paulo; 2006.

10 Gobbi VJ. Influência da nitretação a plasma na resistência ao desgaste microabrasivo do aço ferramenta AISI D2 [dissertação mestrado]. Brasília: Faculdade de Tecnologia da Universidade de Brasília; 2009.

11 Picard S, et al. Corrosion behavior, microhardness and surfasse characterization of low energy, high current ion implanted austenitic stainless steel. Materials Science and Engineering: A. 2001;303(1-2):163-172.

12 Blau PJ. On the nature of running-in. Tribology International. 2006;38(11):1007-12.

* Technical contribution to the $1^{\text {st }}$ Workshop on surface treatments of corrosion resistant alloys, July $21^{\text {st }}-25^{\text {th }}$, 2014, São Paulo, SP, Brazil. 